\title{
Salmeterol/fluticasone stable-dose treatment compared with formoterol/budesonide adjustable maintenance dosing: impact on health-related quality of life
}

\author{
David B Price*1, Angela E Williams ${ }^{2}$ and Sally Yoxall ${ }^{2}$
}

Address: ${ }^{1}$ Department of General Practice and Primary Care, University of Aberdeen, Foresterhill Health Centre, Westburn Road, Aberdeen AB25 2AY, UK and 2Research and Development, GlaxoSmithKline, Greenford Road, Greenford, Middlesex UB6 0HE, UK

Email: David B Price* - david@respiratoryresearch.org; Angela E Williams - angela.e.williams@gsk.com; Sally Yoxall - sally.q.yoxall@gsk.com

* Corresponding author

Published: 4 July 2007

Respiratory Research 2007, 8:46 doi:10.1186/1465-992I-8-46
Received: 5 October 2006

Accepted: 4 July 2007

This article is available from: http://respiratory-research.com/content/8/I/46

(c) 2007 Price et al; licensee BioMed Central Ltd.

This is an Open Access article distributed under the terms of the Creative Commons Attribution License (http://creativecommons.org/licenses/by/2.0), which permits unrestricted use, distribution, and reproduction in any medium, provided the original work is properly cited.

\begin{abstract}
Background: Improving patients' health-related quality of life (HRQoL) is recognized as a fundamental part of asthma management. The aims of this study were to evaluate the long-term efficacy (including symptom-free days and exacerbations) and impact on HRQoL of a stable-dose regimen of salmeterol/ fluticasone propionate (SAL/FP) and an adjustable maintenance dosing (AMD) regimen of formoterol/ budesonide (FOR/BUD) where treatment is adjusted based on symptoms [SAM40056].

Methods: $A$ total of 688 outpatients with asthma receiving regular low-dose inhaled corticosteroids (ICS) plus a long-acting $\beta_{2}$-agonist, or medium dose ICS alone participated in this randomized, double-blind, double-dummy, parallel-group, I-year trial, which was conducted in 91 centers in 15 countries. Patients were randomized to receive I inhalation of SAL/FP 50/250 $\mu \mathrm{g}$ BID or 2 inhalations of FOR/BUD 6/200 $\mu \mathrm{g}$ BID during Weeks I-4. For Weeks 5-52, patients meeting strict continuation criteria for stable asthma at Week 4 received AMD with FOR/BUD or stable-dose SAL/FP.
\end{abstract}

Results: The percentage of symptom-free days was significantly greater $(58.8 \%$ vs $52.1 \% ; p=0.034)$ and the annual exacerbation rate was significantly lower $(47 \% ; p=0.008)$ with stable-dose SAL/FP compared with FOR/BUD AMD. A total of 568 patients completed the Asthma Quality of Life Questionnaire (AQLQ) at least once during the study. The mean change from baseline in AQLQ overall score was numerically greater with SAL/FP than FOR/BUD at week 28 and week 52, but did not reach statistical significance $(P=0.12 \mathrm{I}$ at Week 52$)$. However, in a post hoc logistic regression analyses for any AQLQ improvement, significant benefits with SAL/FP were seen at both time points $(p=0.038$ and $p=0.009$, respectively). The minimally important difference of $\geq 0.5$-point improvement in AQLQ overall score was achieved by a significantly greater number of patients receiving SAL/FP at Week 28 (68\% vs $60 \%$; $p=$ $0.049)$; a trend for this difference remained at Week $52(71 \%$ vs $65 \%)(p=0.205)$.

Conclusion: In this population of patients with persistent asthma, stable-dose SAL/FP resulted in significantly greater increases in symptom-free days, a reduction in exacerbation rates, and provided greater HRQoL benefits compared with FOR/BUD AMD.

Trial registration: Clinical Trials registration number NCT00479739 


\section{Background}

The goals for successful management of asthma are defined as achieving and maintaining symptom control, preventing exacerbations, maintaining lung function as close to normal as possible, preventing asthma mortality and development of irreversible airflow limitation, maintaining normal activity levels and avoiding treatmentrelated adverse effects [1]. In practice, these goals are rarely achieved and asthma control remains poor, with many patients continuing to suffer frequent symptoms and exacerbations [2]. Asthma also has a substantial impact on the health-related quality of life (HRQOL) of patients, with the physical, emotional and social aspects of their lives often considerably impaired [1]. Indeed, in a study investigating patient-defined treatment success, 'improved ability to do normal things' was found to be one of the most important treatment goals, second only to reducing the number of exacerbations [3]. Asthma management guidelines, therefore, recognize the importance of improving patients' daily functioning and wellbeing in addition to improving objective clinical measures of asthma control (e.g. exacerbation reduction) [1]. However, recent research using factor analysis to explore the relationships between $\mathrm{HRQOL}$, measured using the Asthma Quality of Life Questionnaire (AQLQ), and conventional clinical endpoints has demonstrated that HRQoL is a distinct component of asthma health status and is independent of symptom scores or lung function [4]. This supports previous findings that HRQoL measures correlate poorly with clinical parameters, including symptoms and airway caliber [5-9].

Hence, it is not only important for clinical trials to demonstrate that efficacy improvements in response to treatments are clinically meaningful in terms of traditional clinical measures such as control of symptoms and exacerbations; it is also important that they provide further insight from the patient by including an assessment of HRQoL - a patient-reported outcome - using a validated instrument such as the AQLQ. Indeed, the American Thoracic Society and the European Medicines Agency have both issued guidance relating specifically to the measurement of HRQoL $[10,11]$, and the US Food and Drug Administration plan to develop guidance for using patient-reported outcomes during 2005 [12].

In asthma management guidelines, a combination of an inhaled corticosteroid (ICS) and a long-acting $\beta_{2}$-agonist (LABA) is recommended for the treatment of patients not controlled on low or moderate doses of ICS alone [1]. There are two combinations of LABA/ICS currently available in a single device, salmeterol/fluticasone propionate (SAL/FP) and formoterol/budesonide (FOR/BUD), both of which have been demonstrated to significantly improve patients' HRQoL in one-year studies $[13,14]$. The adjustable maintenance dosing (AMD) regimen, which allows patients to adjust their dose of FOR/BUD accord- ing to the severity of their symptoms, has been shown to reduce asthma exacerbations compared with fixed dosing in open-label studies [15-17]. This randomized, doubleblind, double-dummy trial - the CONtrol CEntred Patient Treatment (CONCEPT) - is the first study of this design to have investigated the efficacy and HRQoL effects of stable-dose SAL/FP via Diskus ${ }^{\circledast}$ (trademark of GlaxoSmithKline, Ware, UK) compared with an AMD regimen of FOR/BUD via Turbuhaler ${ }^{\circledR}$ consistent with the current license (trademark of AstraZeneca, Södertälje, Sweden) [18].

\section{Methods \\ Patients}

Full details of the study design and methods have been previously reported [18]. Male and female outpatients (aged 18-<70 years) with a documented clinical history of asthma and forced expiratory volume in 1 second $\left(\mathrm{FEV}_{1}\right)$ $60-90 \%$ of predicted normal were enrolled in the study. All patients had received an ICS dose equivalent to 200$500 \mu \mathrm{g} /$ day beclomethasone dipropionate (BDP) plus a LABA, or ICS alone at a dose equivalent to > 500-1000 $\mu \mathrm{g} /$ day BDP for at least 12 weeks before enrollment. Patients who met any of the following criteria were excluded: a lower respiratory tract infection or use of systemic corticosteroids within 1 month prior to study entry, $\mathrm{a} \geq 10$ pack-year smoking history, changes to regular asthma therapy within 12 weeks of study entry, or any significant disorder that may put the patient at risk or influence study outcomes. Inhaled cromones, leukotriene modifiers, $\beta_{2}$-agonists (except salbutamol as rescue medication), xanthines, and inhaled anticholinergics were not permitted during the study.

\section{Study design}

This was a randomized, double-blind, double-dummy, parallel-group study conducted in 91 centers in 15 countries. During the 2-week run-in period, patients who showed a total daily symptom score of $\geq 2$ on at least 4 of the last 7 evaluable days were eligible for randomization to the 52-week treatment period, which comprised two phases. During the first phase (Weeks 1-4), patients received either 1 inhalation of SAL/FP 50/250 $\mu \mathrm{g}$ BID via Diskus plus 2 inhalations of placebo BID via Turbuhaler or 2 inhalations of FOR/BUD 6/200 $\mu$ g BID (equivalent to $4.5 / 160 \mu \mathrm{g}$ delivered dose) plus 1 inhalation of placebo BID via Diskus.

Patients were eligible to enter the second treatment phase of the study (Weeks 5-52) if they reported no night-time awakenings due to asthma and no salbutamol use on $>2$ days in their diary cards during the 7 days before Visit 3 (i.e. during Week 4). For patients who met these criteria, the Turbuhaler dose was reduced to 1 inhalation BID, with further reduction to 1 inhalation/day if the criteria continued to be met at subsequent visits. If the criteria were not met at later visits, patients reverted to 1 inhala- 
tion BID. Patients also received oral and written information about the AMD self-management plan. Step up of treatment was patient-initiated, whereas stepping down was initiated in consultation with the investigator. The step-up and step-down criteria are detailed in Table 1, and were based on previously published studies [15-17]. For patients with persistent symptoms remaining after 14 days of 4 Turbuhaler inhalations BID, the investigator prescribed a short course of oral corticosteroids and instructed the patient to step down to 1 inhalation BID. Stable dosing with 1 inhalation BID via Diskus was maintained throughout the 52-week, double-blind treatment period. The study was conducted in accordance with the Declaration of Helsinki and good clinical practice guidelines. The study protocol, patient information form and informed consent form were approved by the local ethics committees. All patients provided written informed consent before beginning the study.

\section{Statistical methods and analysis}

The primary efficacy variable was the percentage of symptom-free days, defined as a 24-hour period with a symptom score of 0 (recorded in patients' daily diaries). Additional parameters included the rate of exacerbations, defined as a worsening of asthma requiring hospital treatment or treatment with oral corticosteroids (based on investigator opinion or $\geq 2$ consecutive days with morning peak expiratory flow $(\mathrm{PEF}) \leq 70 \%$ of the mean of the last 7 days of Weeks 1-4).

Efficacy analyses were based on the Intent To Treat (ITT) population (patients who took $\geq 1$ dose of study medication and had $\geq 1$ post-randomization diary assessment). The percentage of symptom-free days was compared between treatment groups using the van Elteren extension to the Wilcoxon rank-sum test, stratified by country grouping. The exacerbation rate was calculated using a maximum likelihood-based analysis assuming the negative binomial distribution, with time on treatment as an offset variable, and the model included adjustments for treatment, sex, country grouping, and age.

The effects of the different treatments on HRQoL were evaluated using the AQLQ at Week 0 (baseline) and Weeks 28 and 52. A within-subject change of 0.5 points was considered the minimal important difference (MID), with a change of $\leq 1$ defined as 'minimal' change, and $>1$ as 'moderate' change $[19,20]$. Mean change from baseline and the distribution of change in AQLQ overall scores were analyzed using analysis of covariance. There was an a priori intent to analyze the proportions of patients achieving MID improvement or deterioration, which was further developed with a post hoc analysis using logistic regression (adjusted for age, sex, country, and baseline AQLQ score), and the overall change in AQLQ at Weeks 28 and 52 investigated in a post-hoc proportional odds regression analysis. A post-hoc descriptive exploratory analysis investigated how many patients in each group demonstrated treatment success defined according to AQLQ changes plus the occurrence of exacerbations (success $=$ AQLQ change of $\geq 0.5$ and no exacerbations; no change $=$ AQLQ change of $>-0.5$ to $<0.5$ and no exacerbations; failure $=\geq 1$ exacerbations with any AQLQ change or AQLQ change $=-0.5$ with no exacerbations). For patients to be included in the post-hoc analysis they needed to have an AQLQ response at the particular visit to be analyzed (i.e. at Week 28 or Week 52).

\section{Results}

A total of 568 patients in the ITT population $(82.6 \%)$ completed the AQLQ at least once during the study; the numbers of patients who completed the AQLQ at each time point are summarized in Table 2 . The baseline characteristics of this AQLQ population were similar to those of the ITT population (Table 3 ).

Table I: Adjustable maintenance dosing plan for active treatment or placebo administered via Turbuhalera during Weeks 5-52.

\begin{tabular}{ll}
\hline Adjustment & Criteria \\
\hline $\begin{array}{ll}\text { Step up: from I or } 2 \text { inhalations/d to } 4 \text { inhalations BID (judged by the } \\
\text { patient) }\end{array}$ & $\begin{array}{l}\text { Two consecutive days or nights with: Rescue medication used } \geq 3 \text { times } \\
\text { during the day } \\
\text { OR }\end{array}$ \\
& Night-time awakening due to asthma \\
& OR \\
& Morning PEF <85\% of the mean of the last 7 days before Visit 3 \\
& Last 2 consecutive days or nights with: \\
Step down: from 4 inhalations BID to I inhalation BID after 7-I4 days of & No rescue medication use \\
step-up treatment (judged by the investigator) & OR \\
& No night-time awakening due to asthma \\
& OR \\
& Morning PEF $\geq 85 \%$ of the mean of the last 7 days before Visit 3
\end{tabular}

$\mathrm{PEF}=$ peak expiratory flow.

aTurbuhaler is a trademark of AstraZeneca, Södertälje, Sweden. 


\section{Efficacy}

Stable dosing with SAL/FP resulted in a significantly higher percentage of symptom-free days compared with AMD with FOR/BUD over the whole 52-week treatment period $(58.8 \%$ vs $52.1 \%$; $\mathrm{p}=0.034)$. Similarly, the percentage of symptom-free days was significantly higher with SAL/FP during Weeks 5-52 (73.8\% vs 64.9\%; $\mathrm{p}=$ $0.030)$. Furthermore, the adjusted annual mean exacerbation rate was $47 \%$ lower in the SAL/FP group compared with the FOR/BUD group ( 0.18 vs 0.33 ; adjusted treatment rate ratio 0.53 [95\% CI: $0.34-0.85] ; \mathrm{p}=0.008$ ). Over the 52-week the mean daily ICS exposure was 463 (81) $\mu \mathrm{g} \mathrm{FP,} \mathrm{in} \mathrm{the} \mathrm{SAL/FP} \mathrm{group,} \mathrm{and} 480$ (238) $\mu \mathrm{g}$ FP in the FOR/BUD group. Efficacy results have been reported in detail elsewhere [18].

\section{Health-related quality of life}

The mean AQLQ overall score at baseline was similar in the two groups (3). The mean change from baseline in AQLQ overall score was greater with stable-dose SAL/FP compared with AMD of FOR/BUD after both Week 28 (1.0 vs 0.8$)$ and Week 52 (1.1 vs 0.9$)$. Statistical significance was tested at the end of the 52-week study period and the difference was found to be not significant ( $\mathrm{p}=$ $0.121)$.

The a priori and post-hoc regression analyses showed that any degree of improvement in AQLQ was achieved by a significantly greater proportion of patients receiving stable-dose SAL/FP compared with the AMD FOR/BUD group at both week 28 (90\% vs $83 \% ; \mathrm{p}=0.038)$ and week $52(91 \%$ vs $81 \%$; $=0.009)$. Similarly, a proportional odds regression analysis, performed post hoc on the categories MID improvement and less than MID improvement/no change against deterioration in HRQoL, showed that the odds ratios for SAL/FP:FOR/BUD at Weeks 28 and 52 were 1.72 (95\% CI: $1.08-2.73 ; \mathrm{p}=0.022)$ and 1.65 (95\% CI: 0.99-2.75; $\mathrm{p}=0.057$ ) respectively. The overall
Table 2: Summary of AQLQ completers at each time point during the study

\begin{tabular}{lcc}
\hline Timepoint & SAL/FP & FOR/BUD \\
\hline Total ITT population & 344 & 344 \\
AQLQ completers & & \\
$\quad$ At least once during study & 280 & 288 \\
$\quad$ Baseline & 278 & 286 \\
Total Week 5-52 population & 295 & 286 \\
AQLQ completers & & \\
$\quad$ Week 28 & $173(59)^{\dagger}$ & $166(58)^{\dagger}$ \\
$\quad$ Week 52 & $158(54)^{\dagger}$ & $155(54)^{\dagger}$ \\
\hline
\end{tabular}

$\mathrm{AQLQ}=$ Asthma Quality of Life Questionnaire; FOR/BUD = formoterol/budesonide combination; ITT = intent to treat; SAL/FP = salmeterol/fluticasone propionate combination.

† Percentage of Week 5-52 population

proportions of patients with at least an MID improvement, a less than MID improvement/no change and deteriorating HRQoL at Week 52 are shown in Table 4.

Looking at the distribution changes in AQLQ score at Week 28 (Figure 1a), 1\% of the SAL/FP group showed deterioration in AQLQ overall score of $\geq 0.5$-point, compared with $7 \%$ of the FOR/BUD group, translating into net benefits (i.e. proportion of patients improving less those deteriorating) of $67 \%$ and $53 \%$ respectively. At 52 weeks (Figure 1b), MID deterioration occurred in $4 \%$ of the SAL/FP group and 5\% of the FOR/BUD group, translating into net benefits of $67 \%$ and $60 \%$, respectively

The post hoc exploratory analysis classifying treatment success or failure based on both AQLQ changes and exacerbations showed that more patients in the SAL/FP group achieved treatment success compared with those in the FOR/BUD group (63\% vs 54\%), whereas fewer SAL/FPtreated patients were classed as showing no change $(23 \%$ vs $26 \%$ ) or failure (14\% vs $21 \%$ ) (Table 5 ).

Table 3: Baseline characteristics of the ITT population and patients who completed the AQLQ at least once during the study

\begin{tabular}{|c|c|c|c|c|}
\hline \multirow[b]{2}{*}{ Characteristics } & \multicolumn{2}{|c|}{ ITT population } & \multicolumn{2}{|c|}{ AQLQ populationa } \\
\hline & SAL/FP & FOR/BUD & SAL/FP & FOR/BUD \\
\hline No. of patients & 344 & 344 & 280 & 288 \\
\hline Age, mean (SD), years & $46(14)$ & $44(14)$ & $45(14)$ & $44(14)$ \\
\hline Sex, female no. (\%) & $204(59)$ & $216(63)$ & $156(56)$ & $178(62)$ \\
\hline Asthma Duration $\geq 10$ years no.(\%) & $197(57)$ & $200(58)$ & $|7|(6 \mid)$ & $162(56)$ \\
\hline $\mathrm{FEV}_{1}$, mean (SD), L & $2.53(0.80)$ & $2.52(0.70)$ & $2.57(0.83)$ & $2.49(0.68)$ \\
\hline $\mathrm{FEV}_{\mathrm{l}}$, mean (SD), \% predicted & $82(21)$ & $81(13)$ & $82(23)$ & $80(12)$ \\
\hline Daily asthma symptom score, mean (SD) & $1.9(0.6)$ & $1.9(0.5)$ & $2.0(0.6)$ & $1.9(0.6)$ \\
\hline AQLQ overall score, mean (SD) & & & $4.8(1.0)$ & $4.8(0.9)$ \\
\hline
\end{tabular}

$\mathrm{AQLQ}=$ Asthma Quality of Life Questionnaire; FOR/BUD = formoterol/budesonide combination; ITT = intent to treat; SAL/FP = salmeterol/ fluticasone propionate combination; $\mathrm{SD}=$ standard deviation.

a ITT patients who completed at least one AQLQ questionnaire. 
Table 4: Patients achieving at least an MID improvement, a less than MID improvement/no change or with deteriorating QoL at Week 52

\begin{tabular}{|c|c|c|}
\hline \multirow{2}{*}{$\begin{array}{l}\text { Week } 52 \\
\mathrm{n}(\%)\end{array}$} & \multicolumn{2}{|c|}{ AQLQ Population } \\
\hline & $\begin{array}{l}\text { SAL/FP } \\
n=158\end{array}$ & $\begin{array}{c}\text { FOR/BUD } \\
n=155\end{array}$ \\
\hline Deterioration in QoL $(<0)$ & $14(9)$ & $29(19)$ \\
\hline No Change/lmprovement $<$ MID $(\geq 0-<0.5)$ & $32(20)$ & $26(17)$ \\
\hline At Least MID Improvement in QoL $(\geq 0.5)$ & $112(7 \mid)$ & $100(64)$ \\
\hline
\end{tabular}

AQLQ = Asthma Quality of Life Questionnaire; FOR/BUD = formoterol/budesonide combination; SAL/FP = Salmeterol/fluticasone propionate combination; $\mathrm{QoL}=$ Quality of Life; MID = minimally important difference.

\section{Discussion}

This is the first study to compare the long-term effects of stable dosing with SAL/FP and an AMD regimen with FOR/BUD on the HRQoL of patients with asthma. The results show that there was improvement in both groups as indicated by the mean change from baseline. However, although greater with stable-dose SAL/FP compared with AMD FOR/BUD, this was not significant. In the post-hoc proportional odds regression analysis, the odds ratio for any improvement in AQLQ against no improvement or deterioration showed a significant benefit for a stable dosing regimen of SAL/FP over a AMD dosing regimen of FOR/BUD at week 28 while there was a trend for benefit at week 52. It is important to note that the use of a doubleblind, double-dummy design minimized any potential for bias resulting from patients knowing which of the treatments was active, a particularly important consideration when both patients and investigators are involved in decisions about medication adjustments. Although the complexity of the study would be decreased with an openlabel design, any control over the influence of such bias

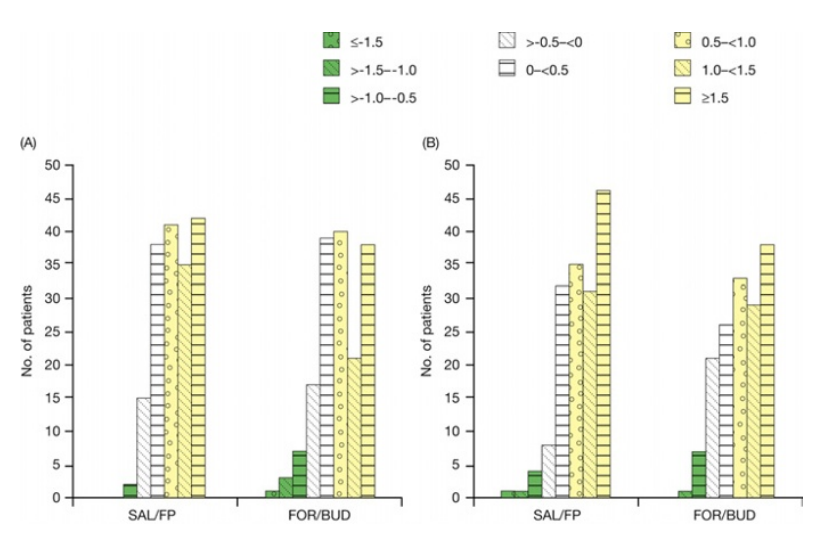

Figure I

Distribution of change in AQLQ overall score at (a) 28 weeks and (b) 52 weeks. AQLQ = Asthma Quality of Life Questionnaire; FOR/BUD = formoterol/budesonide combination; SAL/FP = salmeterol/fluticasone propionate combination.

would be lost. Differences in the licenses for the two study medications may have contributed to the results seen in this analysis, in particularly the license for FOR/BUD allow patients to reduce to one puff/day. This may be more of a risk in the patients with moderate asthma included in this study. With regard to daily, ICS exposure during the 52-week study, as described in the primary paper (18), for the ITT population the mean (SD) daily ICS exposure in the SAL/FP group was 463 (81) $\mu \mathrm{g}$ FP; in the FOR/BUD group, the mean daily ICS exposure was 480 (238) $\mu \mathrm{g}$ BUD.

The significantly greater HRQoL improvement with SAL/ FP at Week 28, and subsequent loss of significance at

Table 5: The percentage of patients achieving treatment success or failure defined according to AQLQ change and exacerbations

\begin{tabular}{|c|c|c|c|c|}
\hline Category & $\begin{array}{l}\text { AQLQ change from } \\
\text { baseline at Week } 52\end{array}$ & Exacerbation & $\begin{array}{c}\text { SAL/FP } \\
n=158 \\
n(\%)\end{array}$ & $\begin{array}{c}\text { FOR/BUD } \\
n=155 \\
n(\%)\end{array}$ \\
\hline Success & $\geq 0.5$ & No & $100(63)$ & $83(53)$ \\
\hline No change & $>-0.5-<0.5$ & No & $36(23)$ & $40(26)$ \\
\hline \multirow[t]{5}{*}{ Failure } & & & $22(14)$ & $32(2 I)$ \\
\hline & $\geq 0.5$ & Yes & $12(7)$ & $17(11)$ \\
\hline & $>-0.5-<0.5$ & Yes & $4(3)$ & $7(5)$ \\
\hline & $\leq-0.5$ & No & $4(3)$ & $3(2)$ \\
\hline & $\leq-0.5$ & Yes & $2(1)$ & $5(3)$ \\
\hline
\end{tabular}

AQLQ = Asthma Quality of Life Questionnaire; FOR/BUD = formoterol/budesonide combination; SAL/FP = salmeterol/fluticasone propionate combination. 
Week 52 is particularly important in terms of supporting the clinical relevance of a regular review for patients with persistent asthma. Patients are recommended to undergo regular clinical review and adjust their dose to maintain asthma control every 1-6 months [1], and the loss of significance at Week 52 may, in part, reflect the fact that patients following the stable dosing regimen of SAL/FP were not permitted to step up the dose of regular therapy to gain asthma control.

The recently reported Gaining Optimal Asthma controL (GOAL) study has demonstrated the benefits to patients of an increasing dose of asthma medication. In the GOAL study, additional benefits were achieved with a strategy of aiming for 'Total Control' of asthma - a rigorous composite definition derived from GINA/NIH management guidelines - with increased doses of SAL/FP until Total Control or maximum study dose was reached [13]. This strategy resulted in benefits to all patients, not just those achieving Total Control. It is possible, therefore, that the potential efficacy and HRQoL effects of this treatment may have been underestimated in the present study with a stable dosing regimen.

Importantly, the GOAL study [13] revealed that an additional $8-12 \%$ of patients achieved Total Control during sustained treatment. Bateman et al postulated that this may reflect more gradual improvements in airway inflammation in response to prolonged dosing $[21,22]$, which may explain the reduction in exacerbations seen with SAL/ FP compared with FOR/BUD in the present study [18]. Previous studies have highlighted the importance of focusing on long-term control of airway inflammation in asthma management [23-26]; determining treatment regimens based on the lowest effective dose that controls symptoms alone does not account for inflammatory changes that can occur in the absence of worsening symptoms and therefore pass unnoticed by patients [27].

Investigating the proportions of change in AQLQ score in this study provides a newer approach to assessing HRQoL, providing deeper insight into the impact of asthma and its treatments on HRQoL. Although the regression analysis was post hoc, the a priori intent had been to investigate the proportions of patients improving or deteriorating by categorizing the changes in AQLQ, following the suggestion that this may help with interpreting the importance of HRQoL results at an individual patient level [28]. This method has been used in other studies comparing asthma treatments [29]. In addition, accounting for patients whose HRQoL deteriorates is important for management strategies; treatments need to increase the proportion of patients who improve and also reduce the proportion of patients who deteriorate.

As HRQoL often correlates poorly with objective measures of clinical improvement, it needs to be measured inde- pendently [29-31]. It is clear that measures of long-term control of airway inflammation such as exacerbation rate should be a focus of asthma treatment. In contrast, the AQLQ only covers a specific period of time so does not directly capture effects on exacerbations that might have occurred outside of this period. As a result, exacerbation rates in clinical trials may vary between treatment arms, whilst HRQoL can remain relatively consistent [31]. In the present study, the endpoint of AQLQ MID improvement plus no exacerbations provides an alternative measure of treatment success that is directly relevant for clinical decision making. With this analysis, more patients receiving $\mathrm{SAL} / \mathrm{FP}$ achieved treatment success than those receiving FOR/BUD.

The HRQoL analysis included a total of $82.6 \%$ of the ITT population although there were no differences in baseline characteristics between the overall and AQLQ populations. This fall in patient numbers can be explained by the fact that not all of the centers participating in the study administered the AQLQ, mainly because a validated translation is not available in all countries. In addition to this, the number of patients completing the AQLQ at Week 4 and then entering the second treatment phase of the study (Weeks 5-52) is the maximum number of patients who could also have values at Weeks 28 and 52. This is a consequence of the study design, which includes strict continuation criteria at Week 4: patients were only eligible to enter the second treatment phase of the study if, in the previous 7 days, they had no night-time awakenings due to asthma and had not used rescue salbutamol on $>2$ days. Ineligibility for continuation led to a reduction of approximately $15 \%$ in the ITT population [18].

The numbers of patients completing the AQLQ in this study as a proportion of those who had entered the second phase were approximately $58-59 \%$ at 28 weeks and $54-55 \%$ at 52 weeks. The attrition rate of over one-third of patients across the 52 weeks further highlights the need for appropriate methodological considerations when measuring HRQoL, such as using electronic data capture to retain patients [32], obtaining a wider range of validated translations of the AQLQ, and increasing the sample sizes to prevent loss of power. Indeed, the decrease in completer rate in the present study and resulting loss of power may have contributed to the lack of statistical significance between the treatment groups at Week 52 despite maintenance of numerical difference in scores between treatment groups.

Patient-reported outcomes such as the AQLQ have a clear role to play in clinical trials. This study shows that stable dosing with SAL/FP provided greater HRQoL and efficacy benefits compared with AMD of FOR/BUD. 


\section{Competing interests}

DP has no shares in pharmaceutical companies. He has received speaker's honoraria for speaking at sponsored meetings from the following companies marketing respiratory products: $3 \mathrm{M}$, Altana, AstraZeneca, BI, GSK, MSD, Novartis, Pfizer, Schering-Plough. He has received honoraria for advisory panels with; $3 \mathrm{M}$, Altana, AstraZeneca, BI, GSK, MSD, Novartis, Pfizer, Schering-Plough. He or his research team have received funding for research projects from: $3 \mathrm{M}$, Altana, AstraZeneca, BI, GSK, MSD, Novartis, Pfizer, Schering-Plough, Viatris. AW and SY are employed by GSK.

\section{Authors' contributions}

DP participated in the design of the analysis and interpretation of the data, and preparation and revision of the draft article. AW interpreted the data, and revised the article. SY performed the statistical analyses, interpreted the data, and revised the article. All authors read and approved the final manuscript.

\section{Acknowledgements}

This study was funded by GlaxoSmithKline Research and Development Limited, Greenford, UK.

\section{References}

I. Global Initiative for Asthma ${ }^{\circledR}$ Global strategy for asthma management and prevention 2004 [http://www.ginasthma.com].

2. Rabe K, Adachi M, Lai CK, Soriano JB, Vermeire PA, Weiss KB, Weiss ST: Worldwide severity and control of asthma in children and adults: the global asthma insights and reality surveys. J Allergy Clin Immunol 2004, I I 4:40-47.

3. Price $D$, Pearson $M$ : What is success in asthma - the patient's view [abstract]. Am J Respir Crit Care Med 1998, I57:A63I.

4. Juniper EF, Wisniewski ME, Cox FM, Emmett AH, Nielsen KE, O'Byrne PM: Relationship between quality of life and clinical status in asthma: a factor analysis. Eur Respir | 2004, 23:287-291.

5. Juniper EF, Guyatt GH, Ferrie PJ, Griffith LE: Measuring quality of life in asthma. Am Rev Respir Dis 1993, 147:832-838.

6. Juniper EF, Norman GR, Cox FM, Roberts JN: Comparison of the standard gamble, rating scale, AQLQ and SF-36 for measuring quality of life in asthma. Eur Respir 」 200I, 18:38-44.

7. Marks GB, Dunn SM, Woolcock AJ: A scale for the measurement of quality of life in adults with asthma. J Clin Epidemiol 1992, 45:462-472.

8. Rutten-van Molken MPMH, Clusters F, Van Doorslaer EK, Jansen CC, Heurman L, Maesen FP, Smeets JJ, Bommer AM, Raaijmakers JA: Comparison of performance of four instruments in evaluating the effects of salmeterol on asthma quality of life. Eur Respir J 1995 , 8:888-898.

9. Leidy NK, Coughlin C: Psychometric performance of the Asthma Quality of Life Questionnaire in a US sample. Qual Life Res 1998, 7:127-134.

10. American Thoracic Society Quality of life resource [http:// www.atsHRQoL.org].

II. European Medicines Agency (EMEA) Reflection paper on the regulatory guidance for the use of health-related quality of life (HRQL) measures in the evaluation of medicinal products (draft) 2004 [http:// www.emea.eu.int/pdfs/human/ewp//3939/04en.pdf].

12. United States Food and Drug Administration Center for Drug Evaluation and Research Guidance Agenda [http://www.fda.gov/cder/guid ance/CY05Agenda-5 1005 finalver.pdf].

13. Bateman ED, Boushey HA, Bousquet J, Busse WW, Clark TJ, Pauwels RA, Pedersen SE, GOAL Investigators Group: Can guideline-defined asthma control be achieved? The Gaining Optimal Asthma ControL Study. Am J Respir Crit Care Med 2004, I 70:836-844.

14. Rosenhall L, Elvstrand A, Tilling B, Vinge I, Jemsby P, Ståhl E, Jerre F, Bergqvist PBF: One-year safety and efficacy of budesonide/formoterol in a single inhaler (Symbicort Turbuhaler) for the treatment of asthma. Respir Med 2003, 97:702-708.
15. Ställberg B, Olsson P, Jorgensen LA, Lindarck N, Ekström T: Budesonide/formoterol adjustable maintenance dosing reduces asthma exacerbations versus fixed dosing. Int J Clin Pract 2003, 57:656-661.

16. FitzGerald JM, Sears MR, Boulet LP, Becker AB, Mclvor AR, Ernst $P$, Smiljanic-Georgijev NM, Lee JS, Canadian Investigators: Adjustable maintenance dosing with budesonide/formoterol reduces asthma exacerbations compared with traditional fixed dosing: a five-month multicentre Canadian study. Can Respir J 2003, 10:427-434.

17. Aalbers R, Backer V, Kava TT, Omenaas ER, Sandström T, Jorup C, Welte T: Adjustable maintenance dosing with budesonide/formoterol compared with fixed-dose salmeterol/fluticasone in moderate to severe asthma. Curr Med Res Opin 2004, 20:225-240.

18. FitzGerald JM, Boulet L-P, Follows RMA: The CONCEPT trial: a Iyear, multicentre, randomized, double-blind, double-dummy comparison of a stable dosing regimen of salmeterol/fluticasone propionate with an adjustable maintenance dosing regimen of formoterol/budesonide in adults with persistent asthma. Clin Ther 2005, 27:393-406.

19. Juniper EF, Guyatt GH, Epstein RS, Ferrie PJ, Jaeschke R, Hiller TK: Evaluation of impairment of health related quality of life in asthma: development of a questionnaire for use in clinical trials. Thorax 1992, 47:76-83.

20. Juniper EF, Guyatt GH, Willan A, Griffith LE: Determining a minimal important change in a disease-specific Quality of Life Questionnaire. J Clin Epidemiol 1994, 47:8I-87.

21. Reddel HK, Jenkins CR, Marks GB, Ware SI, Xuan W, Salome CM, Badcock CA, Woolcock A): Optimal asthma control, starting with high doses of budesonide. Eur Respir J 2000, 16:226-235. correction in Eur Respir J 2000, 16:579.

22. Ward C, Pais M, Bish R, Reid D, Feltis B, Johns D, Walters EH: Airway inflammation, basement membrane thickening and bronchial hyperresponsiveness in asthma. Thorax 2002, 57:309-316.

23. Sont JK, Willems $\mathrm{LN}$, Bel EH, van Krieken JH, Vandenbroucke JP, Sterk P]: Clinical control and histopathologic outcome of asthma when using airway hyperresponsiveness as an additional guide to long-term treatment. The Ampul Study group. Am J Respir Crit Care Med 1999, I59:1043-1051.

24. Green RH, Brightling CE, McKenna S, Hargadon B, Parker D, Bradding $P$, Wardlaw AJ, Pavord ID: Asthma exacerbations and sputum eosinophil counts: a randomized controlled trial. Lancet 2002 , 360:1715-1721.

25. Jayaram L, Hussack P, Efthimiadis A, Boulet LP, Milot J, Lemiere C, Cartier A, Chaibolliez S, Pizzichini E, Pizzichini MM, Hargreave FE: The LOMA study: effect on asthma exacerbations in the first year [abstract]. Am J Respir Crit Care Med 2003, 167:A976.

26. Pizzichini MM, Jayaram L, Pizzichini E, Boulet LP, Lemiere C, Cartier A, Hargreave FE: Does sputum cell counts alter asthma exacerbations? The LOMA study [abstract]. Am J Respir Crit Care Med 2004, 169:A366.

27. De Kluijver J, Evertse CE, Schrumpf JA, van der Veen H, Zwinderman AH, Hiemstra PS, Rabe KF, Sterk PJ: Asymptomatic worsening of airway inflammation during low-dose allergen exposure in asthma: protection by inhaled steroids. Am J Respir Crit Care Med 2002, 166:294-300.

28. Guyatt GH, Juniper EF, Walter SD, Griffith LE, Goldstein RS: Interpreting treatment effects in randomized trials. BMJ 1998, 316:690-693.

29. Juniper EF, Price DB, Stampone PA, Creemers JPHM, Mol SJM, Fireman $P$ : Clinically important improvements in asthma-specific quality of life, but no difference in conventional clinical indexes in patients changed from conventional beclomethasone dipropionate to approximately half the dose of extrafine beclomethasone dipropionate. Chest 2002, I $21: 1824-1832$.

30. Carranza Rosenzweig JR, Edwards L, Lincourt W, Dorinsky P, ZuWallack RL: The relationship between health-related quality of life, lung function and daily symptoms in patients with persistent asthma. Respir Med 2004, 98: I I57-I I 65.

31. Juniper EF, Svensson K, O'Byrne PM, Barnes PJ, Bauer CA, Löfdahl CGA, Postma DS, Pauwels RA, Tattersfield AE, Ullman A: Asthma quality of life during I year of treatment with budesonide with or without formoterol. Eur Respir J 1999, I 4:1038-1043.

32. Bushnell DM, Martin ML, Parasuraman B: Electronic versus paper questionnaires: a further comparison in persons with asthma. J Asthma 2003, 40:751-762. 